\title{
A Comparison of Air Emission Estimation Methods for Drilling Rig Emissions
}

\author{
Susan Stuver ${ }^{1}$, Jesse R. Alonzo ${ }^{1}$, Richard C. Haut ${ }^{2}$, David B. Burnett ${ }^{3} \&$ Forrest H. Cobb ${ }^{1}$ \\ ${ }^{1}$ Texas A\&M Institute of Renewable Natural Resources, San Antonio, Texas, USA \\ ${ }^{2}$ Houston Advanced Research Center, The Woodlands, Texas, USA \\ ${ }^{3}$ Texas A\&M Global Petroleum Research Institute, College Station, Texas, USA \\ Correspondence: Susan Stuver, Texas A\&M Institute of Renewable Natural Resources, San Antonio, Texas, \\ 78209, USA. Tel: 210-277-0292 ext 208. E-mail: s-stuver@tamu.edu
}

Received: March 7, 2015 Accepted: April 7, 2015 Online Published: May 19, 2015

doi:10.5539/enrr.v5n2p158 URL: http://dx.doi.org/10.5539/enrr.v5n2p158

\begin{abstract}
Ever since the Texas Commission on Environmental Quality determined that the Eagle Ford and its supporting industry will be included in future air emission inventories, it has become crucial to identify the most accurate and cost effective methods for determining air emissions of drilling operations. Estimation is the preferred method for creating regional emission inventories since direct measurement of diesel engine exhaust is often cost prohibitive. These estimations are commonly calculated using engine load, conservatively estimated at $100 \%$. This introduces considerable error in the emissions inventory since electric rigs are rarely run at full load and drilling engine activity dramatically varies from job to job. Conducting an air emission inventory of drilling rigs requires a novel way to estimate emissions without relying on engine load as a primary variable. With this in mind the research team employed an estimation method based on fuel consumption rather than horsepower. Fuel use data is readily available on drilling sites and so more accurately reflects the engine activity of electric rigs in drilling operations. This study finds that calculated emissions can vary from 9 to 106 pounds per hour of NOx depending on the estimation method used. Given the deviation that can occur in estimation, the fuel consumption method offers an opportunity for more accurate, cost-effective assessment of regional emission inventories.
\end{abstract}

Keywords: air quality, emissions, air emission inventories, drilling emissions, emission estimation, diesel engine

\section{Introduction}

There are three main methods for collecting air emissions data. It can be directly measured at the engine tailpipe, it can be measured through ambient, downwind monitoring, or it can be estimated through a collection of engine data, fuel data and emission factors for the family of engines being studied. Since direct emission measurement of all emission sources in an air emission inventory can be limited by funding, time, or staff size, estimation is typically used to determine the air quality impact from a particular industry (United States Environmental Protection Agency [USEPA], 2014).

The Texas Commission on Environmental Quality has determined that the Eagle Ford and its supporting industry will be included in future air emission inventories. However, the current methods for estimating emissions impose significant error in the inventory thus compounding the variance between regional air shed models. These high levels of variance result from the quality of the data being entered into the equations as well as the equations themselves.

In this study, we attempt to determine the best way to estimate emissions from drilling operations. Researchers from the Institute of Renewable Natural Resources (IRNR) teamed with industry partners to determine the most accurate method for estimating emissions from drilling rigs via data collection directly from energy producers with active operations in the Eagle Ford Shale Play.

Since drilling engines have high variability in engine load, conducting an air emission inventory of drilling rigs requires a novel way to estimate emissions without relying on engine load as a primary variable. The team therefore employed an alternative calculation that used fuel consumption data rather than total horsepower and engine load data. This method appeared to minimize the error significantly, giving a more accurate picture of drilling engine activity. 
This project was conducted by Texas A\&M IRNR which is part of the Environmentally Friendly Drilling Systems Technology Integration Program (managed by the Houston Advanced Research Center - HARC and the Texas A\&M Global Petroleum Research Institute - GPRI).

\section{Materials and Methods}

\subsection{Planning}

Planning for the drilling rig study began with the formation of the Eagle Ford Air Emission Inventory Group, which consisted of Texas A\&M Agrilife Research, Alamo Area Council of Governments (AACOG), ConocoPhillips, Chesapeake Energy, Marathon Oil, Carrizo, EOG Resources, HOLTCAT, Pioneer Natural Resources, Energy Transfer, Plains Exploration and Production, Shell Oil and the Texas Oil and Gas Association (TxOGA).

Initial meetings consisted of introductory presentations and a description of how emissions inventories are typically calculated. Operators became increasingly concerned about the accuracy of emission inventory methods; specifically that emissions inventories multiply total potential engine load by total available horse power. According to drilling engineers participating in the group, generator engines for electrical rigs rarely run at full engine load and there may be several engines located on site as back-up that are not running at all. Furthermore, since engine load can fluctuate dramatically during a drilling operation, standardization poses a sizable challenge with risk of significant error. Therefore, it was agreed that using fuel consumption as an alternative method to using total potential horsepower and engine load would yield a clearer picture of actual emissions. What resulted was a refined equation for estimating emissions from drilling rigs based on fuel consumption.

\subsection{Data Collection}

Fuel consumption data was simpler to obtain than engine load data and could be acquired directly from the operators without site visits or the acquisition of highly sensitive engine controller data from the service providers. This is appreciable since most air emission inventories are survey driven and do not include site visits or nondisclosure agreements.

Data was collected by submitting a survey to nine participating companies within the Eagle Ford Air Emission Inventory Group operating within the Eagle Ford Shale Play.

The following data was gathered on the survey for both mechanical and electric drilling rigs:

1) Company Name

2) Year for which data was given - in this case, 2012

3) Number of wells drilled in 2012

4) Number of rigs used in 2012

5) Annual hours rigs operated in 2012

6) Cumulative depth drilled (in feet)

7) Emission control type (tier 1,2,3 or 4)

8) Fuel type used (diesel, natural gas etc.)

9) Gallons of fuel consumed

10) Percent of time ancillary equipment (Loaders, forklifts, pumps etc) was used

11) Percent of old engines replaced with tier 4 by 2015

12) Percent of old engines replaced with tier 4 by 2018

13) Equipment class (example Patterson, Trinidad etc.)

14) Number of engines used in drilling operation

15) Total available horsepower of each engine

16) Engine model year

17) Engine make and model (example Caterpillar, Cummins, Detroit etc.)

Field data from the surveys were compared with default data from literature using the fuel consumption method as explained further in the materials and methods section. Additionally, emission results from the fuel consumption method were compared with emission results from the horsepower method. 


\section{Data Analysis}

\subsection{Understanding Emission Factors}

In order to understand how emissions are estimated, it is first necessary to understand emission factors. Emission factors are often averages of available data and assumed to be representative of all emissions within a certain source category. They are representative values which relate the quantity of pollutants released into the atmosphere to the activity releasing the pollutants and are expressed as the weight of the pollutant divided by unit weight, volume, distance, or duration of the activity emitting the pollutant (USEPA, 2014). The emission factor is used to calculate the total emission from a source as an input for an emission inventory (USEPA, 2014).

The general USEPA (2014) equation for emission factor development is:

$$
\mathrm{E}=\mathrm{A} \times \mathrm{EF} \times(1-\mathrm{ER} / 100)
$$

where

$\mathrm{E}=$ emissions; $\mathrm{A}=$ activity rate; $\mathrm{EF}=$ emission factor; $\mathrm{ER}=$ overall percentage emission reduction efficiency.

General emission factors are available to the public. However, variations in engine conditions can significantly affect the emissions at an individual location depending on temperature of combustion or emission controls; the development of local emission factors is highly advantageous and will provide more accurate estimations (USEPA, 2014).

Emissions of criteria pollutants are usually given as mass of pollutant emitted per mechanical energy produced by the engine, (i.e. $\mathrm{g} / \mathrm{kWh}$ ). The energy developers participating in the study reported using Caterpillar $3512 \mathrm{C}$ diesel generator sets that were rated Tier 2.

Emission values that were most representative of $3512 \mathrm{C}$ engines were found on the California Air Resources Board (CARB) certificate (CARB, 2007). These criteria pollutant values were derived from zero hour steady state emissions tests performed by the manufacturer on 3512C engines operating at nominal power and speed.

Slightly more conservative than CARB, the USEPA also publishes emission standards that may be used as factors for this particular engine make and model. These values constitute allowable emissions when factors such as engine deterioration and less than nominal operational conditions are taken into consideration. These values may be used in lieu of the CARB certificate values but are generally much more conservative.

Next there are the USEPA (1996) AP-42 which publish much generalized factors for engines greater than 750 horse power. The AP-42 divides the values into controlled and uncontrolled factors for oxides of nitrogen or NOx. Controlled factors account for associated emission controls on large engines, while uncontrolled factors make the assumption that the engine has no emission controls for NOx (ie tier zero).

Table 1 gives the range of various emission factors and standards that are allowable for use when conducting an emission inventory with the aforementioned engine type. Note that both USEPA emission standards and CARB emission factors combine the NOx and volatile organic compounds (VOCs) into a single number which is referred to as non-methane hydrocarbon plus NOx (NMHC+NOx) in Table 1. The CARB Air Quality Management District guidelines outlined in Moyer (2005) were used to separate the two values into NOx and VOC which states that emission factors for NOx equals $95 \%$ of the total sum NMHC+NOx.

The VOC values for AP-42 NOx controlled and uncontrolled engines were obtained from an USEPA total organic carbon (TOC) value which according to the USEPA (1996) is $9 \%$ methane and $91 \%$ non-methane by weight. Therefore, the original TOC values of 0.43 were adjusted for both controlled and non-controlled engines by multiplying 0.91 . The remainder of criteria pollutants (VOCs, CO and PM) are the same for both controlled and uncontrolled engines because the "controls" in USEPA (1996) refers to NOx only.

Table 1. Allowable Emission Factors and Standards $(\mathrm{g} / \mathrm{kWh})$ for Emission Inventories of Caterpillar 3512C engines as listed by USEPA, CARB, and AP-42 Sources

\begin{tabular}{lccccc}
\hline Emission Factors/Standards & NMHC NOX & NOX & VOC & PM & CO \\
\hline Caterpillar 3512C Emission Factor CARB & 5.3 & 5.04 & 0.27 & 0.14 & 1.6 \\
Caterpillar 3512C Emission Standard - USEPA & 6.4 & 6.08 & 0.32 & 0.2 & 3.5 \\
AP42 Controlled Engine greater than 750 hp & & 7.91 & 0.43 & 0.43 & 3.35 \\
AP42 Uncontrolled Engine greater than 750 hp & & 14.6 & 0.43 & 0.43 & 3.35 \\
\hline
\end{tabular}




\subsection{Calculation using Fuel Consumption Method with Field Data}

The amount of No. 2 diesel (gallons) used to drill a well was averaged on a per hour basis for 41 electric rigs operating in the Eagle Ford Shale play throughout 2012. The resulting average was 55 gallons of diesel used per hour for a typical diesel Tier 2, 3512C Land Drilling Generator Set Engine. The gallon per hour (gal $/ \mathrm{hr}$ ) average was converted to pounds per hour (lb/hr) using the average density for No. 2 diesel of 7 pounds per gallon (lb/gal) (American Petroleum Institute, 1988). By applying this conversion factor the calculated fuel use average of an electric rig is $385 \mathrm{lb} / \mathrm{hr}$.

Engine data used was for a 2008, Tier 2, Diesel Compression-Ignition off-road engine listed as engine family: 8CPXL58.6T2X (CARB, 2007). Based on interviews with drilling engineers, 50\% load for Brake Specific Fuel Consumption (BSFC) of No. 2 Diesel on the $3512 \mathrm{C}$ drilling rig generator sets was considered typical for a drilling operation in the Eagle Ford.

The CARB (2007) certificate emission factor for the 3512C Tier 2 engine used most often by the energy developers, who participated in this study, is the NMHC+NOx CARB emission factor. As previously described, the CARB emission factor for NOx in table 1 was derived from the NMHC+NOx CARB emission factor.

Calculation of NOx emissions using the fuel consumption method with the CARB emission factor and field data proceeded as follows:

The emission factor was converted from $\mathrm{g} / \mathrm{kW}-\mathrm{hr}$ to $\mathrm{lb} / \mathrm{hp}-\mathrm{hr}$;

Emission Factor for NOx $=5.04 \mathrm{~g} / \mathrm{kW}-\mathrm{hr}$ x $(\mathrm{lb} / 453.59 \mathrm{~g} \mathrm{x} \mathrm{kW/1.3405} \mathrm{hp})=0.008280 \mathrm{lb}=0.008 \mathrm{lb}$

$$
\text { NOx } / \mathrm{hp}-\mathrm{hr}
$$

and used in the equation for pounds of NOx per hour which yielded the following;

$$
\begin{aligned}
{\left[\mathrm{E}_{\mathrm{l}} \mathrm{lb}_{\mathrm{NOx}} / \mathrm{hr}\right.} & =\left\{\left[\text { Fuel Usage } \mathrm{avg}_{\text {avg }}(\mathrm{lb} \text { fuel } / \mathrm{hr})\right] /[\mathrm{BSFC}(\mathrm{lb} \text { fuel } / \mathrm{hp}-\mathrm{hr})]\right\} \times\left(\mathrm{EF}_{\mathrm{NOx}}\right)=\mathrm{lb}_{\mathrm{NOx}} / \mathrm{hp}-\mathrm{hr} \\
& =(385 \mathrm{lb} \text { fuel } / \mathrm{hr}) /(0.35 \mathrm{lb} \text { fuel } / \mathrm{hp}-\mathrm{hr}) \times\left(0.008 \mathrm{lb}_{\mathrm{NOx}} / \mathrm{hp}-\mathrm{hr}\right)=9.1 \mathrm{lb}_{\mathrm{NO}} / \mathrm{hr} .
\end{aligned}
$$

Carbon Monoxide (CO), VOC, and Particulate Matter (PM) were also calculated and are mentioned in the results section of this report.

\subsection{Calculation using Fuel Consumption Method and Default Data}

Emission standards from the USEPA for the 1,476 horsepower 3512C Land Drilling Generator Sets were chosen as a default standard (USEPA, 1996). This would be the factor most likely chosen in an emission inventory if the engine make and model was known but little else about the operation. Standards for NOx, CO, VOC and PM were calculated based on the fuel input factors provided from AP-42 (USEPA, 1996).

The No. 2 diesel fuel usage value of 69.5 gallons per hour was provided on the Caterpillar technical data sheet for the 3512C Land Drilling Generator Set as a "nominal" or best guess value (Caterpillar, 2013). This value represents a possible default when field data was unavailable, and was used to calculate the default fuel consumption emissions.

Calculating NOx emissions using the fuel consumption method with USEPA 3512C Emission Standard listed in table 1 and default data proceeded as follows:

The emission standard was converted from $\mathrm{g} / \mathrm{kW}-\mathrm{hr}$ to $\mathrm{lb} / \mathrm{hp}-\mathrm{hr}$ :

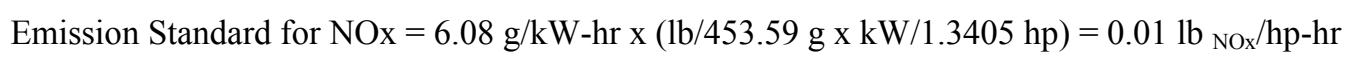

and used in the equation for pounds of NOx per hour which yielded the following:

$$
\begin{aligned}
{[\mathrm{E}] \mathrm{lb}_{\mathrm{NOX}} / \mathrm{hr} } & =\left\{\left[\text { Fuel Usage } \mathrm{avg}_{\text {avg }}(\mathrm{lb} \text { fuel } / \mathrm{hr})\right] /[\mathrm{BSFC}(\mathrm{lb} \text { fuel } / \mathrm{hp}-\mathrm{hr})]\right\} \times\left(\mathrm{EF}_{\mathrm{NOx}}\right)=1 \mathrm{~b}_{\mathrm{NOX}} / \mathrm{hp}-\mathrm{hr} \\
& =(486.5 \mathrm{lb} \text { fuel } / \mathrm{hr}) /(0.33 \mathrm{lb} \text { fuel } / \mathrm{hp}-\mathrm{hr}) \times\left(0.01 \mathrm{lb} \mathrm{b}_{\mathrm{NOx}} / \mathrm{hp}-\mathrm{hr}\right)=14.74 \mathrm{lb}_{\mathrm{NOX}} / \mathrm{hr} .
\end{aligned}
$$

$\mathrm{CO}, \mathrm{VOC}$, and PM were also calculated and are mentioned in the results section of this report.

\subsection{Calculation using the Traditional Horse Power Method}

The horse power method is the traditional approach to air emission inventories, derived by multiplying the emission factor, the total available horsepower, and the engine load together to achieve pollutant emissions in pounds per hour. Since engine load can fluctuate dramatically during a drilling operation, collecting engine load field data is typically not an option and is therefore conservatively estimated at $100 \%$. Hourly emission rates were calculated using conservative default emission factors for NOx controlled diesel engines found in the AP-42 (USEPA 1996). 
In order to make an effective comparison, the same diesel operated 1,476 horsepower Caterpillar, Tier 2, 3512C drilling generator sets were used in examining both the horse power and fuel consumption methods. There are three of these generator sets on site for a typical drilling operation in the Eagle Ford so that total horsepower is calculated as:

$$
\text { 1,476 hp x } 3 \text { engines }=4,428 \mathrm{hp}_{\text {total. }} \text {. }
$$

The emission equation for NOx follows:

$$
\mathrm{E}_{\mathrm{NOx}}=\mathrm{EF} \times \mathrm{HP}_{\text {total }} \mathrm{x} \mathrm{LF}
$$

where

$\mathrm{E}_{\mathrm{NOx}}=\mathrm{NO}_{\mathrm{x}}$ Emissions $(\mathrm{lb} / \mathrm{hr})$;

$\mathrm{EF}_{\mathrm{NOx}}=\mathrm{NO}_{\mathrm{x}}$ Emission Factor ( $(\mathrm{b} \mathrm{NO} / \mathrm{hp}-\mathrm{hr})$;

$\mathrm{HP}_{\text {total }}=$ Total potential power output (hp);

$\mathrm{LF}=\mathrm{Load}$ factor (assumed to be $100 \%$ ).

Calculating NOx emissions using the horsepower method with the default AP-42 NOx Controlled Emission Factor listed in table 1 proceeded as follows:

The emission factor was converted from $\mathrm{g} / \mathrm{kW}-\mathrm{hr}$ to $\mathrm{lb} / \mathrm{hp}-\mathrm{hr}$;

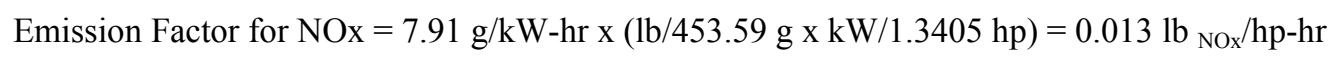

then NOx emissions were calculated using the horse power method, yielding;

$$
\mathrm{E}_{\mathrm{NOx}}=0.01 \mathrm{lb} / \mathrm{hp}-\mathrm{hr}(100 \%) 4,428 \mathrm{Hp}=57.64 \mathrm{lbs}_{\mathrm{Nox}} / \mathrm{hr}
$$

$\mathrm{CO}, \mathrm{VOC}$, and PM were also calculated and are located in the results section of this report. Note that the AP-42 uncontrolled factor for NOx is twice as high as it is for controlled engines. Therefore, if we were to substitute the uncontrolled engine factor into the equation, the emissions estimation for NOx would increase significantly.

For example, when the USEPA AP-42 NOx Uncontrolled Emission Factor was used:

The emission factor was converted from $\mathrm{g} / \mathrm{kW}-\mathrm{hr}$ to $\mathrm{lb} / \mathrm{hp}-\mathrm{hr}$;

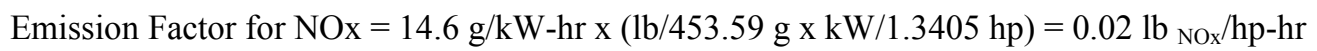

Calculation of NOx using this factor represents the most conservative emission estimation, yields the following;

$$
\mathrm{E}_{\mathrm{NOx}}=0.02 \mathrm{lb} / \mathrm{hp}-\mathrm{hr}(100 \%) 4,428 \mathrm{Hp}=106.32 \mathrm{lbs}_{\mathrm{Nox}} / \mathrm{hr} .
$$

\section{Results}

\subsection{Making the Comparisons}

Calculations were performed for each of the criteria pollutants using each of the protocols described in the sections above. Results as listed in Table 2 indicate that pounds of pollutants reported for the same operation could vary as much 97.21 pounds depending on the protocol chosen.

Table 2. Emissions Results of Two Estimation Methods Using Available Factors and Standards(lb/hp-hr)

\begin{tabular}{lcccc}
\hline & \multicolumn{2}{c}{ Fuel Consumption Method } & \multicolumn{2}{c}{ Traditional Horsepower Method } \\
\hline & Field Data and & Default Data and & AP-42 NOx & AP-42 NOx Uncontrolled \\
& CARB Emission & USEPA Emission & Controlled Emission & Engine Emission Factor \\
NOx & 9.11 & Standard & Factor & 106.32 \\
VOC & 0.48 & 14.74 & 57.60 & 2.84 \\
PM & 0.25 & 0.77 & 2.84 & 3.13 \\
CO & 2.89 & 0.48 & 3.13 & 24.40 \\
\hline
\end{tabular}




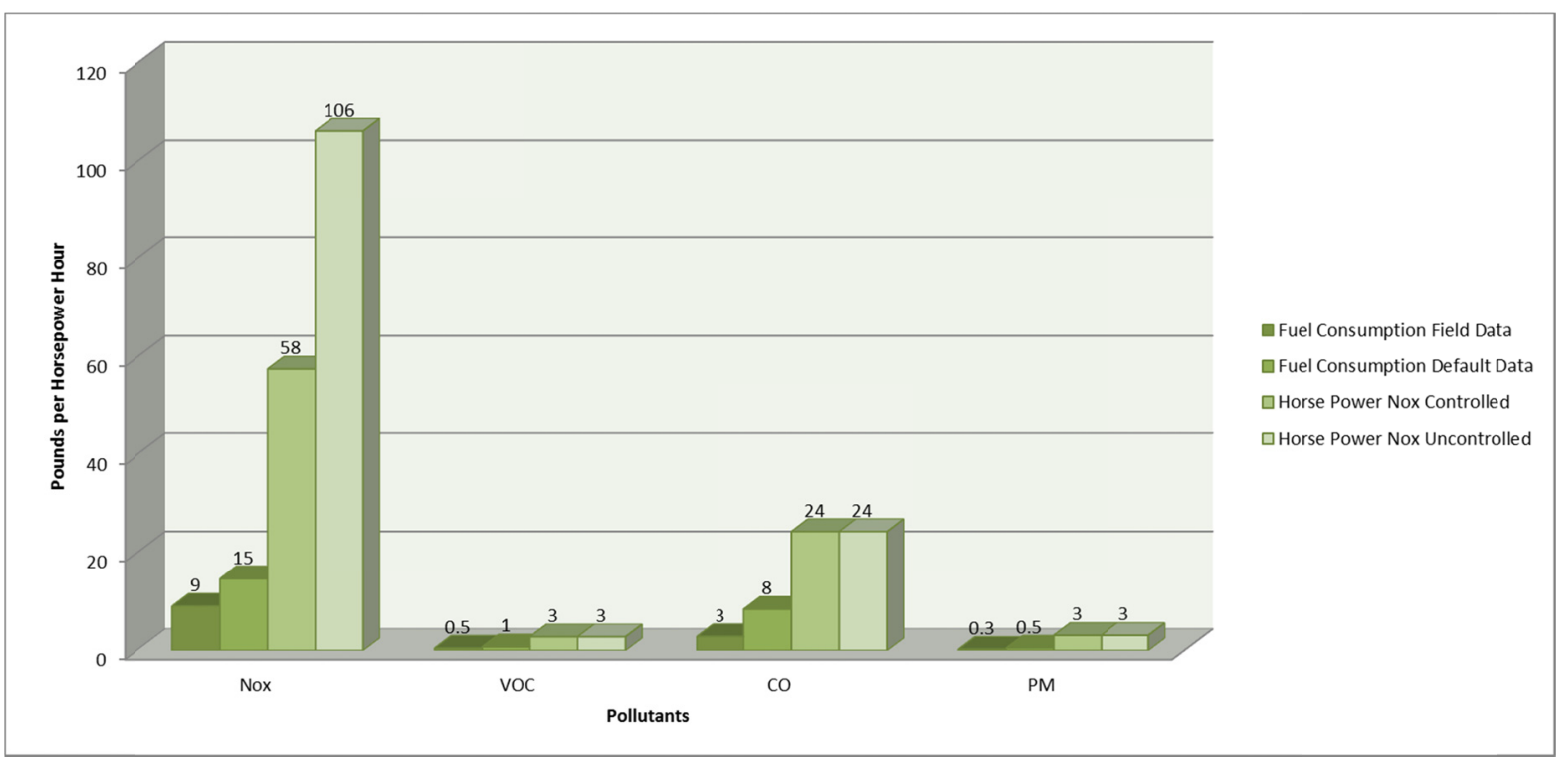

Figure 1. Comparison of Air Emission Inventory Protocols for the Same Drilling Operation (lb/hp-hr)

\section{Discussion}

\subsection{The Right Protocol for the Right Job}

For the same operation, results varied from 9 to 106 pounds per hour for NOx depending on the protocol chosen. On average, using fuel consumption to calculate emissions rather than total horse power yielded a lower pound per hour rate. This was expected since the horse power method was reliant upon a default $100 \%$ engine load and assumed that generators were all operational at all times. Estimating emissions with the fuel consumption method uses data that more accurately reflects engine activity under field conditions.

With that said, the question becomes - if the fuel consumption method yields more accurate results for drilling operations, then why not use this method for hydraulic fracturing operations as well? The answer is that data availability varies depending which operation is being studied. On a hydraulic fracturing site, acquiring fuel consumption data for individual engines (such as the hydraulic fracturing pumps for instance) can be quite challenging since fuel is typically supplied by 1 or 2 tanker trucks and then routed throughout the pad for a whole host of activities and many types of equipment. Engine load from fracturing pumps however remains fairly stable and can be estimated with some degree of confidence. Therefore, using the horsepower method may be the best option in that situation.

In a drilling operation however, it is the opposite. Fuel consumption data is fairly simple to obtain since only 2 or 3 generators supply power for the electric rigs. Whereas drill rig generator engine load is highly variable; changing dramatically throughout the job and adjusted to account for well depth, geologic formation, type of petroleum product being extracted, type of well drilled, type of mud used, type of equipment used and company philosophy. So for this type of activity, it might be best to consider using the fuel consumption method.

\section{Conclusion}

Since drilling engines have high variability in engine load, conducting an air emission inventory of drilling rigs requires a novel way to calculate emissions. That is, a way to estimate emissions without relying on engine load as a primary variable. Fuel consumption data is readily available in a drilling operation and so provides an opportunity for more accurate assessment of drilling operation emissions. However, for other upstream operations such as completions, traditional methods that utilize horse power and engine load as variables may be better suited if fuel consumption data is unavailable.

Most importantly, the emission results of an air emission inventory can dramatically vary depending on the type of calculations and methods chosen. In order to achieve the most accurate results, use as much field data as possible as well as emission factors that are best suited to the engines being inventoried. 


\section{References}

American Petroleum Institute. (1988). Table B-1. In Alcohols and Ethers Publication No. 4261 (2nd ed.), Washington, DC. Retrieved from http://www.methanol.org/energy/resources/alternative-fuel/alt-fuelproperties.aspx

California Air Resources Board. (2007). Executive Order U-R-001-0337 for New Off-Road Compression-Ignition Engines. Engine Family 8CPXL58.6T2X. Retrieved from http://www.arb.ca.gov/ msprog/offroad/cert/eo/2008/ofci/u-r-001-0337.pdf

Caterpillar. (2013). 3512C Land Drilling Generator Set Technical Data Sheet. Retrieved from https://catoilandgas.cat.com/cda/ files/2180106/7/LEHW0068-01\%20P5.pdf

ConocoPhillips. (2014). Drilling and Extracting Planning. Retrieved from http://www.conocophillips.com/ what-we-do/producingenergy/oil-and-gas/onshore/Pages/drilling-and-extracting.aspx

ECOpoint. (2004). Non-Road Diesel Tiered Engine Standard Description. Retrieved from http://www.dieselnet. com/standards/us/nonroad.php

Emission Standards for Stationary Diesel Engines. (2004). 40 C.F.R. Part 69 38. Retrieved from $\mathrm{http} / / / \mathrm{www} . e p a . g o v / \mathrm{ttn} / \mathrm{caaa} / \mathrm{t3} / \mathrm{fr} \_$notices/diesel_anpr_011608.pdf

Moyer, C. (2005). Table 5-2, p V-3. In The Carl Moyer Program Guidelines Part II of IV - Project Criteria. Retrieved from http://www.arb.ca.gov/msprog/moyer/guidelines/2005_Carl_Moyer_Guidelines_Part2.pdf

United States Environmental Protection Agency. (1996). Chapter 3.4 - Large Stationary Diesel and All Stationary Dual-fuel Engines and AP-42, Table 3.4-1 sub-note f. In AP-42. 5th Edition. Retrieved from http://www.epa.gov/ttnchie1/ap42/ch03/final/c03s04.pdf

United States Environmental Protection Agency. (2014). Air Quality Management Online Portal. Retrieved from http://www.epa.gov/airquality/aqmportal/management/emissions_inventory/emission_factor.htm

\section{Copyrights}

Copyright for this article is retained by the author(s), with first publication rights granted to the journal.

This is an open-access article distributed under the terms and conditions of the Creative Commons Attribution license (http://creativecommons.org/licenses/by/3.0/). 